\section{Cureus}

Received 07/18/2018

Review began 07/21/2018

Review ended 07/21/2018

Published 07/23/2018

\section{(๑) Copyright 2018}

Alimi et al. This is an open access article distributed under the terms of the Creative Commons Attribution License CC-BY 3.0., which permits unrestricted use, distribution, and reproduction in any medium, provided the original author and source are credited.

\title{
Radial Artery Injury with Attempted Intravenous Catheterization on the Dorsal Hand: A Case Report
}

\author{
Yusuf Alimi $^{1}$, Joe Iwanaga ${ }^{2}$, Rod J. Oskouian ${ }^{3}$, Marios Loukas ${ }^{4}$, R. Shane Tubbs ${ }^{5}$
}

1. Anatomy, St. George's University School of Medicine, St. George's, GRD 2. Medical Education and Simulation, Seattle Science Foundation, Seattle, USA 3. Neurosurgery, Swedish Neuroscience Institute, Seattle, USA 4. Medical Education and Simulation, St. George's University School of Medicine, St. George, GRD 5. Neurosurgery, Seattle Science Foundation, Seattle, USA

$\square$ Corresponding author: Joe Iwanaga, joei@seattlesciencefoundation.org

Disclosures can be found in Additional Information at the end of the article

\section{Abstract}

Intravenous (IV) access on the dorsum of the hand is of high clinical significance. As it is possible for an arterial injury during IV access on the dorsum of the hand to occur, clinicians and healthcare providers should be cognizant of regional anatomy and anatomical variations during IV placement so as to prevent injuries to the radial artery. We report a case of an injury to the radial artery with an attempted hand IV placement in a cadaver and suggest possible ways to prevent this complication.

Categories: Pathology, Miscellaneous

Keywords: radial artery, injury, intravenous, anatomy

\section{Introduction}

Venous access is of high clinical importance, as it allows for blood sampling as well as the administration of medications, fluids, nutrition, and chemotherapy [1]. The history of intravenous (IV) therapy can be traced back to the Middle Ages in the earliest attempts to transfuse blood [2]. It has since been a cornerstone of medical practice all over the globe, with almost every surgical patient requiring the placement of an IV catheter [3]. However, IV placement has not been without complications. The well-known complications include dysfunctional catheters and catheter-associated infections [4]. Injuries to peripheral nerves have been reported, along with thrombosis and phlebitis of the vessel involved [3-4]. Herein, we report a case of an injury to the radial artery, with attempted IV placement into the hand, found during cadaveric dissection.

\section{Case Presentation}

During a routine dissection of the dorsal hand in a male cadaver, a large hematoma (Figure 1) was identified on the dorsal surface of the right hand. Both subcutaneous hematoma and a hematoma within the first dorsal interosseous muscle were found. The skin overlying this area was found to have tributaries of the cephalic vein within it. After the removal of the subcutaneous part of the hematoma, the radial artery, after traversing the anatomical snuffbox, was seen entering the two heads of the first dorsal interosseous muscle in the normal fashion. As the intramuscular part of the hematoma was adjacent to the radial artery, microdissection of this adjacent vessel was performed and a puncture site with thrombosis found in the adventitia of this vessel. Therefore, the diagnosis of radial artery puncture with resultant hematoma was 


\section{Cureus}

made. No other disease or pathology of the hand was noted and no grossly visible anatomical variations were noted.

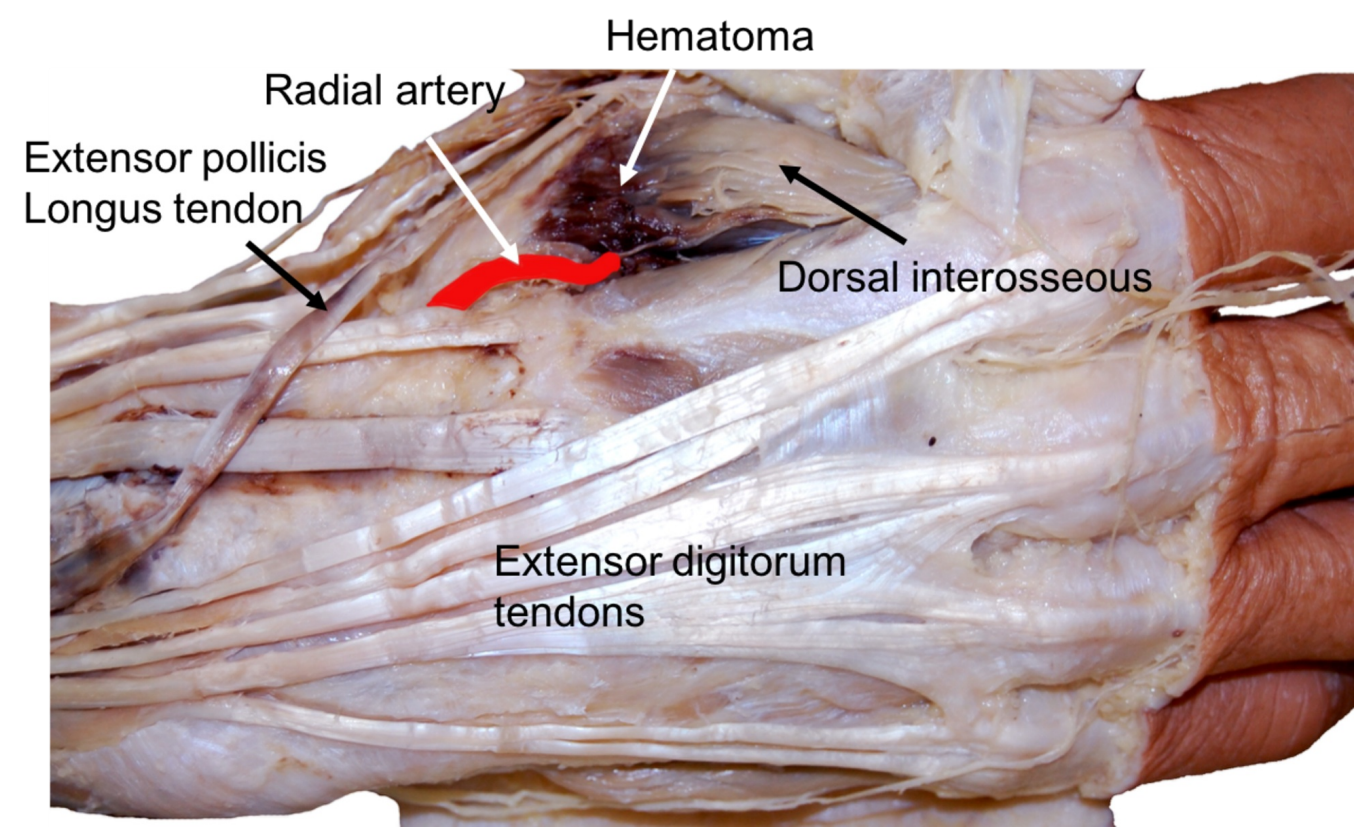

\section{FIGURE 1: Right hand of the case presented herein}

Note the hematoma involving the first dorsal interosseous muscle and the relationship to the radial artery, which has been colored red for clarity.

\section{Discussion}

The radial artery originates from the brachial artery after the later bifurcates in the cubital fossa. This bifurcation is delineated by imaginary lines between the epicondyles superiorly, the medial border of the brachioradialis laterally, and the lateral border of the pronator teres muscle medially [5-6]. It then runs distally, taking a lateral path around the wrist and crossing the floor of the anatomical snuff box, which is typically bordered by the tendons of the extensor pollicis longus medially and the extensor pollicis brevis and abductor pollicis longus tendons laterally [5-6]. The cephalic vein runs on the dorsum of the hand, across the anatomical snuffbox, and is a common site of peripheral venous access and venipuncture [7-8]. Reports of atypical superficial branches of the radial artery in the hand, as well as its high origin from the brachial artery, are well documented [9-11] and since the dorsum of the hand is an area frequently used for IV access, a change in the normal course of the artery makes it susceptible to iatrogenic injury during these procedures $[5,12]$.

One case report identified a patient with an atypical radial artery lodged superficially to the abductor and extensor pollicis longus tendons [12]. This superficial radial artery was mistaken for a vein due to its unusual anatomy. The patient underwent cannulation of the mistaken radial artery for post-operative IV administration [12]. Five days post cannulation, the patient presented with ecchymosis and darkening of the skin over the right thumb and index finger. It is well-established that an intra-arterial injection is a cause of pain, tissue necrosis, and ischemia at distal locations supplied by the vessel [13]. Physical examination findings indicated the loss of Doppler signals in the palm during ulnar artery occlusion (positive Allen's test) and a purple appearance at the tip of the thumb, suggestive of a vascular injury to the radial artery [12]. An arteriogram showed the occlusion of the radial artery-secondary to thrombosis-and 
although thrombectomy and surgical repair of the radial artery were performed, the patient underwent amputation of the first two digits secondary to necrosis a month after the procedure [12]. Therefore, a good understanding of the anatomy and variants of the dorsal hand in regard to IV placement is essential for those placing such catheters [14-15].

\section{Conclusions}

Although an understanding of the anatomy and variations of the radial artery are important when performing a venipuncture procedure on the dorsum of the hand, careful observation along with perioperative imaging studies (e.g., ultrasound) can help avoid complications. Injury to the radial artery can be minimized by palpating for a pulse before attempted catheterization and by not advancing the needle too deeply. Healthcare personnel should be aware of the possibility of injury to the radial artery and its surrounding neurovascular structures so as to prevent potentially serious and unwanted complications such as the large hematoma found in our case.

\section{Additional Information Disclosures}

Human subjects: Consent was obtained by all participants in this study. Conflicts of interest: In compliance with the ICMJE uniform disclosure form, all authors declare the following:

Payment/services info: All authors have declared that no financial support was received from any organization for the submitted work. Financial relationships: All authors have declared that they have no financial relationships at present or within the previous three years with any organizations that might have an interest in the submitted work. Other relationships: All authors have declared that there are no other relationships or activities that could appear to have influenced the submitted work.

\section{References}

1. Todd J: Peripherally inserted central catheters and their use in IV therapy . Br J Nurs. 1999, 8:140-148. 10.12968/bjon.1999.8.3.6699

2. Rivera AM, Strauss KW, van Zundert A, Mortier E: The history of peripheral intravenous catheters: how little plastic tubes revolutionized medicine. Acta Anaesthesiol Belg. 2005, 58:271-282.

3. Boeson MB, Hranchook A, Stoller J: Peripheral nerve injury from intravenous cannulation: a case report. AANA J. 2000, 68:53-57.

4. Schmid MW: Risks and complications of peripherally and centrally inserted intravenous catheters. Crit Care Nurs Clin North Am. 2000, 12:165-174. 10.1016/s0899-5885(18)30108-4

5. Lirk P, Keller C, Colvin J, Colvin H, Rieder J, Maurer H, Moriggl B: Unintentional arterial puncture during cephalic vein cannulation: case report and anatomical study. Br J Anaesth. 2004, 92:740-742. 10.1093/bja/aeh118

6. Standring S: Gray's Anatomy: The Anatomical Basis of Clinical Practice. New York, Elsevier Limited; 2016.

7. Sadeghi A, Mehr MS, Esfandiari E, Mohammadi S, Baharmian H: Variation of the cephalic and basilic veins: a case report. J Cardiovasc Thorac Res. 2017, 9:232-234. 10.15171/jcvtr.2017.40

8. Matsuo M, Honma S, Sonomura T, Yamazaki M: Clinical anatomy of the cephalic vein for safe performance of venipuncture. JA Clin Rep. 2017, 3:50. 10.1186/s40981-017-0121-6

9. Gupta C, Ray B, Dsouza AS, Nair N, Pai SR, Manju M: A morphological study of variations in the branching pattern and termination of the radial artery. Singapore Med J. 2012, 53:208211.

10. Nayak SB, Kumar N, Padur AA, Shetty SD: Variant superficial branch of radial artery along with supplementary tendons on the dorsum of the hand and their surgical implications. Case Rep Surg. 2016, 2016:1-3. 10.1155/2016/9581759

11. Bhanu PS, Sankar KD, Susan PJ: High origin and superficial course of radial artery . IJAV. 2010, 3:162-164. 


\section{Cureus}

12. Beale E, Behnam A: Injection injury of an aberrant superficial radial artery requiring surgical intervention. J Hand Microsurg. 2016, 4:39-42. 10.1007/s12593-011-0053-8

13. Ghouri AF, Mading W, Prabaker K: Accidental intraarterial drug injections via intravascular catheters placed on the dorsum of the hand. Anesth Analg. 2002, 95:487-491.

14. Miletin J, Sukop A, Baca V, Kachlik D: Arterial supply of the thumb: systemic review . Clin Anat. 2017, 30:963-973. 10.1002/ca.22973

15. Umemoto K, Ohmichi M, Ohmichi Y, et al.: Vascular branches from cutaneous nerve of the forearm and hand: application to better understanding Raynaud's disease. Clin Anat. 2018, 31:734-741. 10.1002/са.22993 